\title{
II
}

\section{The Siberian Shaman's Technique of Ecstasy}

\author{
By ANNA-LEENA SIIKALA
}

The Siberian shaman's function as mediator between the normal and the supranormal world is based on systems of beliefs according to which difficulties threatening the even peace of life are caused by representatives of the spirit world, and can be forestalled and eliminated with the help of benevolent spirits. There are several methods used in the areas in which shamanism appears that are thought to influence the working of supranormal beings. The essential feature in the functioning of the shaman is the creation of direct and reciprocal states of communication directed at the spirit world. The shaman is thus first and foremost a supplier of information and a "negotiator", whose task is to find out the measures required to resolve a crisis that has already arisen or to prevent crises in the future. Although the tasks of the shaman vary somewhat in different communities, they do have one thing in common in that direct communication with the spirit world is always considered necessary in carrying out the shaman's duties. A shamanic rite is not made shamanistic merely by the nature of the task to be carried out, i.e. the aim of the rite, but by the way in which the goal is sought. The shamanic rite is an attempt to solve the problems of the normal world through ecstatic contact with the supranormal.

\section{Shamanism and the altered states of consciousness}

The Siberian shaman's technique of ecstasy, regarded sometimes as symptomatic of a pathological state and sometimes as "cold-blooded" playacting, is one link in a series of extensive phenomena highly varied in form. The anthropological literature uses the words trance, ecstasy and possession as general terms for given states. The last of these, sometimes wrongly used as a synonym for the first two, arises from culturally-bound concepts. It is based on native theory according to which a supranormal being may enter a person's body and take command. As terms, 'trance' and 'ecstasy' 
do not differ greatly from each other except that the former is favoured primarily by anthropologists, the latter by students of comparative religion. They both refer to forms of behaviour deviating from what is normal in the wakeful state and possessing a specific cultural significance, typical features being an altered grasp of reality and the self-concept, with the intensity of change ranging from slight modifications to a complete loss of consciousness. Recent research has adopted the general term, altered states of consciousness, ASC's, to express this sphere.

In order to be able to understand or interpret correctly the incomplete reports of ecstasy and possession based on the momentary impressions of eyewitnesses appearing in ethnographic literature, the reader must be familiar with the features characteristic of altered states of consciousness. The matter cannot be approached completely objectively. The scale describing the outward behaviour of the ecstatic, and similarly his feeling or observations, is very broad. The same external stimulation may also, in the case of various individuals, lead to ASC's differing from one another. As I shall attempt to show later, the factors leading to personal ASC experiences lie at many levels and are always weighted according to the demands of the situation and the motivations and hopes of each individual (van der Walde 1968 , 56). The subjective content of experience is influenced by what is culture dependent, e.g. belief, frames of reference the ecstatic has learnt to associate with ASC's, i.e. during his trance the shaman meets his spirithelper, a Christian possibly Christ or the Virgin Mary. Differences in the nervous systems of individuals also affect their responses to various stimuli and thus shape the nature and degree of the alteration of consciousness. The phenomena classified as altered states of consciousness do, however, have certain common features with the help of which their close relationship can be shown. Arnold Ludwig has tried to define these natural properties, whilst emphasizing that some are more, some less typical of different individual cases. He mentions alteration in thinking, disturbed time sense, loss of conscious control, change in emotional expression, body image changes, perceptual distortions, hallucinations and pseudo-hallucinations, change in meaning or significance, sense of the ineffable, hypersuggestibility (Ludwig 1968, 77-83).

Examining shamanic phenomena in the light of Ludwig's list of features, we see that most of the properties he mentions well describe the state reached by the shaman during his ritual activity. Changes in the field of observation and body image, attenuated grasp of reality and self-control, which may lead to identification with authority in the case of the shaman with supranormal powers, are all identifying features of shamanic ecstasy. It also appears that some of the basic elements of the shamanic tradition 
can be explained on the basis of typical marks of identification of altered states of consciousness. A sense of depersonalization and transcendence may in itself act as an impetus to cosmic journey fantasies. Without doubt, such feelings are at the very heart of the tradition containing the schism between mind and body. Thus, by placing the shamanic technique of ecstasy beside parallel modes of behaviour, possibly of different cultural background, we discover the guide lines for analysing its basic psychophysical properties.

The ways in which people have pursued trance or an altered state of consciousness, or found themselves in such a state, are generally speaking highly varied, ranging from mechanical stimuli of the nervous system to chains of effect caused by such mental factors as states of mind and motivations. We may, however, mention four regions of the human organism the disturbance of whose balance, in one way or another, leads to altered consciousness. These are a) the normal inflow of sensory stimuli, b) the normal outflow of motor impulses, c) the normal 'emotional tone', or d) the normal flow and organization of processes of recognition.'

Arnold Ludwig has presented an extensive list of the methods used in the pursuit of an altered state of consciousness. He divides these methods into five groups, according to the nature of the technique, and points out that different methods may overlap. ${ }^{2}$

1. Reduction of exteroceptive stimulation and/or motor activity:

- result of absolute reduction of sensory input, changes in pattern of sensory data, or constant exposure to repetitive, monotonous stimuli.

— includes hypnotic trance; ASC's from prolonged social isolation, e.g. mystics, aescetics.

- (lethargy of initiation period)

2. Increase of exteroceptive stimulation and/or motor activity and/or emotion:

- excitatory mental states resulting mainly from sensory overloading or bombardment, which may or may not be accompanied by strenuous physical activity or exertion. Profound emotional arousal and mental fatigue may be major contributing factors.

- dance and musical trance in response to rhythmic drumming; hyperkinetic trance states associated with emotional mental contagion, often in a group or mob setting; religious conversion and healing trance experiences during

1 Ludwig 1968, 30; see also Fischer 1969 ánd 1970. The part played by emotion as a factor leading to ecstatic behaviour has attracted the attention, above all, of students of mysticism and deep religious experiences. Orlo Strunk links the arousal of emotion with the process of perception and finds himself on the track of one fundamental fact in saying that the closer perceived aspects (concerning religion) come to self-concept, the greater is the attendant emotional experience. Strunk 1962, 67. See also Sundén 1959, $49 \mathrm{ff}$.

2 Ludwig 1968, 71-75. Quoted here is Sheila $S$. Walker's summary, which concentrates in particular on a broad presentation of the parts that concern institutionalized and religious connections Walker 1972, 12. 
meatings of a revivalist type; mental aberrations associated with certain rites of passage; spirit possession states; shamanistic, divinatory, prophetic and ecstatic trances.

3. Increased alertness or mental involvment:

- results from focused or selective hyperalertness and from peripheral hyperalertness for prolonged periods.

- fervent praying; total involvment in listening to dynamic speaker; trance resulting from watching a revolving object.

4. Decreased alertness or relaxation of critical faculties:

- passive state of mind with minimum of active, goal-directed thinking.

5. Presence of somatopsychological factors:

- results from alterations in body chemistry, or neurophysiology, which are deliberate or due to a situation over which the individual has no control.

- drowsiness; dehydration; hypoglycemia from fasting; (hyperventilation); hormone disturbance; sleep deprivation.

It is interesting to note that the $\mathrm{ASC}$ technique appearing in religious connections cover all five of IJudwig's classes. For example, the pursuit of trance through meditation comes under classes 1 and 4, the mass frenzies brought on by charismatic preachers under class 3. Ludwig places shamanism in the group 'Increase of exteroceptive stimulation and /or motor activity and/ or emotion', but it is clear that the use of hallucinogens he places in class 5 also serves to characterise the shamanic technique of ecstasy (Cf. Harner 1973). It appears from some of the reports of shamanizing that the séance is preceded by a period of concentration, a type of meditation (Jochelson 1926, 205), which is in marked opposition to the strongly motoric behaviour of the séance itself. A study should be made of the types of combinations appearing among forms of shamanism representing different cultures. The most common Siberian hallucinogen, for example - amanita - is not used everywhere (Siikala 1979). In some areas it is among the normal, revered tools of the shaman, in others it marks out the user as belonging to a class of poorer or less skilled shamans. From the reports of séances we can also observe clear regional differences in the motor behaviour of the shaman. Thus Ludwig is right to suggest that the means of ecstasy he classifies may possibly overlap. The technique of ecstasy, especially in its ritual connections, seems to constitute a cumulative process in which factors aiming at the same result but operating at various levels of man's psychophysical mechanism act as mutual reinforcements. These component processes may also come in succession. Sheila $S$. Walker notes that the initial stages of possession trance may be due to one factor, later stages to a different one (Walker 1972, 12-13). Thus the shamanic séance, like many other enactions of cult, begins as a current given momentum by rhythmic music, dance and song. We may then think 
of a gradual alteration of consciousness induced by sensory stimulation as opening the way to mechanisms at a psychological level.

Changes in states of consciousness are moulded by many factors: external stimuli, personal expectations and motives, social, cultural and situational demands, even properties connected with the inherited psychophysical make-up of the aspirant. In the most highly patterned connections, even the combination of so many variables leads to individual differences. On the other hand, when studying a phenomenon such as shamanism, where the method of inducing trance is marked by the occurrence of certain common features and whose culturally-bound meaning and social function are, broadly speaking, uniform, we may assume that despite individual variation the basic mechanism of the technique of ecstasy may be delineated. What, then, is the ideal process of the shamanic trance technique? What factors exert particular pressure on the behaviour of the shaman? On the basis of Ludwig's classification we may already conclude that some of these factors have a 'mechanical' influence at the neurophysiological level, whilst others are among more complicated brain functions, i.e. are formed from processes of a psychic nature.

In setting out to discover a basic psychic mechanism for the shaman's technique drawing on a knowledge of Western hypnosis, I wish to emphasize immediately that it is impossible to make an exact equation between these phenomena. Differences in cultural environment, cognitive system and functional context, alone, push them in different directions. Also of great importance is the fact that the Western hypnotic trance does not involve any of the neurophysiological changes discernible by EEG that are most clearly characteristic of shamanic ecstasy. ${ }^{3}$ Thus although the shaman's technique of ecstasy does display many factors influencing at a neurophysiological level which do not appear in Western hypnosis - the use of hallucinogens will suffice as one such factor-I consider that the basic psychic process by which the shamanic trance is channelled into a specific form and content is the same as the process of influence in hypnosis. ${ }^{4}$

The induction phase of hypnotic trance has been analysed best by those researchers who have stressed the nature of the phenomenon as goaloriented striving or social interaction. Mention should be made in this sense, above all, of two theorists with complementary views each illuminating our understanding of the shaman's technique of ecstasy: Ronald E. Shor

3 See Raymond Prince's list of features indicating neurophysiological changes, Prince $1968,121$.

4 New studies concerning the active-alert in- duction of a hypnotic-like ASC support this assumption, see Bányai 1980, Bányai-Hilgard 1976, Bányai-Mészáros-Greguss 1980. 
and Theodore Sarbin. Both set out to develop the theories of Robert W. White which stress the importance of motivation as a basic element of hypnotic behaviour and which are crystallized in the following definition: "hypnotic behaviour is meaningful, goal-oriented striving, its most general goal being to behave like a hypnotized person as this is continuously defined by the operator and understood by the subject"' (White 1941, 483).

Ronald E. Shor's article "Hypnosis and the concept of the generalized reality-orientation" is significant in the sense that it tries to show how an alteration in consciousness occurs as a result of this goal-orientend striving. He starts from the theory that a normal state of consciousness is characterized by the mobilization of a structured frame of reference behind the attention which supports, interprets and gives meaning to all experience. This frame of reference he calls the usual generalized reality-orientation (Shor 1959, 585). Generalized reality-orientation develops slowly during life and remains a superstructure of consciousness only by means of active mental striving, which in fact is not usually conscious. According to Shor hypnosis is a complex of two fundamental processes. The first is the construction of a special, temporary orientation to a small range of preoccupations and the second is the relative fading of the generalized realityorientation into non-functional unawareness (Shor 1959). This basic process of the altering of awareness, or actually the two fundamental processes, illustrates the psychich mechanism by which the shaman attains a state of trance. To the shaman preparing for a séance his generalized realityorientation remains without significance. He directs all his energy towards active performance, by means of which he recalls the other reality to which only he has access, the shamanic world. His special temporary orientation is directed at shamanic knowledge.

Shor himself points out that this basic mechanism of hypnotic trance was in fact described earlier, only with the emphasis on slightly different aspects: "While the concept of new, special orientation is defined from the standpoint of cognition, it is identical with what White has called goaloriented striving from the standpoint of motivation or what Sarbin has called role-taking from the standpoint of social psychology" (Shor 1959, 598).

The supranormal shamanic world is personified in separate supernatural beings which, being capable of communication, are social beings. Correspondingly the shamanic séance as a forum for communication between this world and the next is a social occasion at which the shaman, as medium, holds reciprocal relationships with both sides. If we assume that the basic psychic mechanism of the shaman's technique of ecstasy is the same as that in Western hypnotic practices or, on an even wider scale, in all trance 
behavior, ${ }^{5}$ Theodore Sarbin's socialpsychological formulation "hypnosis is one form of a more general kind of social psychological behavior known as role-taking"' (Sarbin 1950, 255) then provides the analytically most fertile point of departure for studying this mechanism. This view does not contradict the explanation starting from a personality psychology basis, according to which controlled trance phenomena can be explained as regression in the service of the ego. ${ }^{6}$ The reason why, in examining shamanism, the socialpsychological aspect takes precendence over the personality-psychological is simply that the former provides a better terminological and conceptual frame of reference for the sounding of the social dimensions of an institutionalized phenomenon. ${ }^{7}$

\section{The conditions for controlled ecstatic behaviour}

Although social reasons, such as the striving for prestige or material advantage in the case of poor young men, may lead a man to become a shaman (cf. Bogoras 1904-1909, 424), the bulk of the shamans' own personal reports give "the shaman's disease" as the basic stimulus. The story of the wife of Shaman Kyzlasov is typical: "That was how he became a shaman, after the sickness, after the torture. He had been ill for seven years. While he was ailing, he had dreams: he was beaten up several times, sometimes he was taken to strange places" (Diószegi 1960, 58). The symptoms are both mental and physical; there are frequent mentions of pains in the head and the limbs, states of torment, with visions and voices, fits reminiscent of manifestations of hysteria, and so on. The patient turns to shamanizing in order to be healed, and this means is often mentioned as being the last and the only way of attaining equilibrium. Whatever the nature of the psychophysical disturbances that the symptoms of shaman's so-called sickness refer to, it is clear from the reports that equilibrium can be attained and maintained precisely by shamanizing. Often the shaman's account mentions that neglect of shamanizing causes a return of the sickness. If the shaman's initiatory sickness is equated with hysteria, as is done by many scholars,

${ }^{5}$ Cf. the view put forward by van der
Walde, based on cross-cultural comparisons,
according to which the basic mechanism of
hypnotic trance is the same as that in all goal-
oriented trance behaviour van der Walde
1968 .
6 On the theory of hypnosis as controlled
regression, se Merton M. Gill and Margaret
Brenman 1959 .
7 Hjalmar Sundén and Lauri Honko have
mapped out the potential of role theory spe- cifically as an explanation of the psychological prerequisities for the encounter between man and the supranormal (Sundén 1959 and Honko 1972). In his article "Role-taking of the Shaman" (1969) Honko has also discussed the shaman's art of social role-changing. In my earlier publication "The Rite Technique of the Siberian Shaman" (1978) I have deliberated these principal ideas and paid special attention to the concept of roletaking. See also Peters-Price-Williams 1980. 
the novice stage must be regarded as a therapeutic period during which the initiate, generally under the guidance of an older shaman, learns to order and control his ego-functions by means of ready models within the belief tradition so that a real fit of hysteria during the initiatory stage becomes a fit in the control of the ego. No universally accepted conclusions as to the nature of the shaman's initiatory 'sickness' have been made, however, and it is difficult or even impossible to draw any from the wide range of symptoms mentioned in the reports. It is more or less agreed that one feature of the shaman novice is some sort of nervous sensitivity or reactional susceptibility. When we remember, for example, that the future shaman of a clan may be selected for training even as a child, that seeking to become a shaman may be influenced by social reasons and, above all, that even a person with a normal nervous constitution may be means of a suitable technique reach an altered state of consciousness, ${ }^{8}$ it is obvious that it is impossible to name any specific nervous disorder qualifying a person as a shaman. The basic qualification for becoming a shaman is control of the technique of ecstasy and the formal study of this technique. People with a certain nervous susceptibility are, however, best suited for this, and people easily roused to hysteria have the best potential. Thus it is often exceptional individuals who seek to become or are sought out as shamans. The long initiatory stage is then preparation for the control of ecstatic behaviour. The shaman must execute faultlessly traditionally-patterned ritual functions before the critical eyes of an audience.

Study centres round ways of using mechanical means of stimulating the nervous system - rhythmical music, singing, dancing and drugs - as best suits each individual, and practice in the psychic mechanism of the technique of ecstasy. The psychic side of the shaman's technique of ecstasy may be regarded as a phenomenon related to Western hypnotic behaviour, in which an altered state of consciousness is attained as a suggestive consequence of dynamic experience. As a result of the shaman's position as a vehicle of communication between this and the other world, this experience takes place by means of role-taking directed at representatives of the spirit world. The assumption of the role of the other is a covert cognitive process which denotes the ability to place oneself symbolically in the place of another. ${ }^{9}$ Living the spirit roles, manifesting them to the point of identification does, however, mean that these roles have been learnt.

\footnotetext{
${ }^{8}$ See i.e. Andrew Neher (A physiological explanation of unusual behavior in ceremonies involving drums, 1962) and V. J. Walter and W. G. Walter (The central effects of rhythmic sensory stimulation, 1949).
}

${ }^{9}$ On role-taking and the role-concepts of symbolic interactionism, see Mead 1934, Sarbin 1950 and 1954, Turner 1956, Allen-Sarbin 1964, Cooley 1972. 
Sarbin and Allen, for example, who observed that role-taking and roleperformance concern man's entire psychophysical being, stressed the need for previous experience in a role-taking situation (Sarbin-Allen 1969, 522-523). During his initiation period the novice constructs his supranormal counter-roles in accordance with the models provided by tradition, i.e. he acquires his spirit-helpers. The way in which the young shaman selects elements of the belief tradition in shaping his supranormal helpers is illustrated in the shaman's songs and the visions requiring a deeper assimilation of the tradition. For example, the songs of the Chukchi shaman, based on tradition but moulded into individual shapes, came into being precisely during the novice stage. The content of the songs is to a great extent the shaping of supranormal roles: they describe the regions inhabited by the spirits, the essence of the spirits and their characteristic features, the tasks they are able to carry out, and so on (Siikala 1980, 88-92). The ways of manifesting the spirit roles are also traditional. Shirokogoroff, for example, describes typical modes of behaviour of the Manchu shaman from which the shaman's assistant and those present can recognise the spirit in question (Shirokogoroff 1935, 337). The ecstatic experiences of the initiation period, which shamans have, when interviewed, been able to describe feature by feature, are repeated in the songs sung during séances. There are frequent references for example to the motif of 'the dissecting of the shaman by spirits', i.e. the culmination of the process of becoming a shaman, the 'birth' of the shaman. It is interesting, as appears from the initiatory visions of the Samoyed shaman, that these experiences are completely traditional not only in content but also in form (Siikala 1978, 193-197). In other words the structure of the visions is in the main similar, and the motifs are repeated in the songs sung while shamanizing.

\section{The induction of trance}

In public ritual proceedings the technique of ecstasy transferring the shaman to an altered state of consciousness appears as a cumulative process in which elements acting at the physical and mental levels reinforce one another. In addition to a mechanical stimulus (rhythmic music in the case of Siberian shamans), the following suggestive factors affect the change in consciousness: a) the motivation of the shaman, which may be social (there is an acute need for the séance) and recognised or may lie in the realm of unrecognised personal hopes and wishes, b) study by the shaman of matters representing the supranormal, c) the actively expressed concentration of the attention, hopes and wishes of the audience on the shaman and d) a strong emotional pressure that is the sum of all these elements. It is characteristic of the course of the séance that these factors influence the 
séance in different ways at different stages, and the degree of change in the shaman's consciousness likewise varies. I shall here attempt to outline the basic features of the shamanic technique of trance and to distinguish the factors shaping the shaman's ecstatic behaviour.

The preparation for the séance is the stage at which ties with the ordinary waking state, the normal world, are broken. The séance may be preceded by a period of fasting or contemplation. Whether the period of concentration is long or short, it includes the assembly of requisites and the donning of the shaman's dress, these representing the concrete transition to the faculty of shaman. The dress, on which are depicted the shaman's supranormal assistants or other objects necessary for moving about in the spirit world, in itself helps to focus the shaman's thoughts. All measures taken during the preparatory stage - the tuning of the drum, the removal of any icons, which were already relatively common by the end of the 19th century, the extinguishing of the fire, the making of idols, the excitement and hushed expectation of those present - generate favourable emotional charges in those present and above all help the shaman to concentrate on his coming task as shaman and on the supranormal helpers required in the task.

The induction proper of trance, the stage at which the shaman attains an altered state of consciousness, is, according to shamanic theory, the period of assembling the spirit-helpers. Practices are surprisingly similar throughout Northern and Central Asia. The chief principle may be described as follows: connected with the rhythmical, sensory stimulus slowly gaining momentum and directly influencing the central nervous system is the gradual actualisation of the supranormal counter-roles and a slowly intensified assumption of supranormal roles in conjunction with the sensory stimulus. It has been experimentally proved that rhythmical stimulus alone is sufficient to bring about changes in the electrical activity of the brains of people with normal nerves and, according to the reports of the test subjects, it also produces unusual observations (Neher 1962). The shaman's drumming technique is by and large uniform over the whole area: a slow, soft initial phase is followed by an increase in tempo and volume. The effect of the rhythmical stimulus is in some areas fortified by various intoxicants, such as amanita, and in latter times in particular strong tobacco and alcohol. The use of hallucinogens and other such intoxicants is not, however, a vital element of trance technique in any part of Siberia. The mechanical stimuli mentioned thus form a necessary basis for the shaman's trance behaviour. Shamanic practice does, however, differ from other means of attaining ecstasy with its emphasis on the ritual role-taking technique aimed at the supranormal counter-roles, the "spirit-helpers". The shaman's gen- 
eralized reality orientation is cut off by means of suitable ritual requisites, the extinguishing of the lights and the noise of intensified drumming. Its place is taken by special orientation, a world created by the shamanic tradition, fantasies of supranormal beings and their dwelling places. The shaman actualises one spirit role after another according to a set pattern. Very often (e.g. in the shaman's songs of the Khants (Karjalainen 1918, 558-591), the Nentsy (Lehtisalo 1947, 493-496), and the Chukchi (Findeisen 1956, 141-156)) the shaman, in calling on his spirits, almost as it were brings them concretely near him. The objects described in the song are firstly the figure of the spirit and its dwelling in the other world, then the spirit's journey to the shaman stage by stage, reaching its climax with the arrival at the séance. The course of the account of the journey described in an invocatory song such as this coincides with the curve representing the rise in ecstatic frenzy on the part of the shaman, i.e. during the songs the shaman reaches an altered state of consciousness. The invocation of the spirit-helpers during the induction of the trance may be manifested more simply. The imitation of the sounds of the spirit-helpers, constituting the first act of the most common séance, is one of the most established elements of the séance. More precisely, this is the imitation of the sound of spirits imagined to be in animal form, and this acts almost without exception in the function of a call. Corresponding growling, whistling and other sounds are also encountered later in the séance, but then it is a question of manifesting the spirit roles present. Simple shouts of invocation or request to the spirits for help fall in between the songs, dividing them up into shorter entities. Note that the nature and scope of the invocatory songs seems to correlate with the modes of manifesting the spirit roles. Instead of a long description of the spirit world there may simply be a statement of the reason for the séance and request for help (cf. Orochi séances, Lopatin 1946-1949, 365-368). In such cases improvisation plays a relatively large part in contrast, for example, to the long poetic song episodes of the Nentsy (Lehtisalo 1947).

The audience plays a relatively small part at the trance induction stage. It chiefly concentrates on supporting the shaman through invocations or urgings addressed to the spirits. Many observers mention a growing expectation, which is a feature characteristic of the opening stages of the séance. The part played by the audience is probably greater at this stage as an emotional factor. The shaman feels the weight of expectation as he concentrates on his performance. 


\section{Variations in the presentation of spirits}

Meetings with the spirit-helpers, either in this world or the other, constitute the ecstatic climaxes of the séance. As the shaman manifests his supranormal counter-roles his consciousness has already clearly altered. This degree of alteration is not, however, the same in different séances, nor does it remain constant within the course of one séance. The depth of the shaman's trance varies in the different stages of the séance, and he may from time to time rest in order to seek ecstasy again. In addition to individual differences arising from ecstatic ability the depth of the trance also seems to be regulated by traditionally bound factors. Comparison of the descriptions of séances shows that the supranormal counter-roles are manifested by means of a few alternative techniques. These are: a) the shaman identifies completely with the spirit role, he is regarded as having changed quite concretely into a spirit (role-identification); b) manifesting both his own role as a shaman and that of the spirit, the shaman creates a dialogue situation in which the spirit is regarded as acting and speaking from outside the physical being of the shaman (dual role); c) the shaman creates an image of the role performances of his spirit-helpers purely verbally, in which case only the shaman is regarded as "seeing" or "hearing" the spirits during the séance (description of counter-role).

Complete role-identification, which is common in Central and Eastern Siberia (among e.g. the Yukagir (Jochelson 1926, 196-199), Evenks (Anisimov 1963, 100-105), Yakuts (Hudjakov 1969, 311-355), Manchu (Shirokogoroff 1935, 308-309, 313-314), Nanay (Lopatin 1960, 169-172) and Orochi (Lopatin 1946-1949, 365-368) signifies possession. One or more spirithelpers is thought to enter the body of the shaman and to speak and act through him. Jochelson's description of the changing of a Yukagir shaman into a spirit is highly characteristic: "The shaman half-opens the door and inhales his spirits in deep and noisy breaths. Then he turns to the interior of the house, holds his hands like claws, rolls his eyes upwards, so that only the whites are seen, sticks out his tongue, curling it under the chin and, without uttering a word, walks to the centre of the house and sits down on the ground. Having sat down, he straightens his hands and pulls his tongue in with his eyes still turned upwards and a blown up belly he sits there and already one of the spirits speaks through him" (Jochelson 1926, 201). Features that recur are a) the arrival of the spirit at the door, b) the inhaling of the spirits and c) the expression of the spirit's nature in words, mimicry and movement: a Manchu shaman, transformed into a wolf, claws the ground like a wolf (Shirokogoroff 1935, 337) and an Orochi shaman transformed into a bird leaps across the tent shouting, "I fly, I fly" (Lopatin 1946-1949). As regards the role relations of the séance, the shaman's 
complete identification with one of his supranormal counter-roles means that the position of the shaman as a mediator between the two worlds remains, as it were, unfilled. Role-identification is regularly followed by the someone present at the séance, usually the assistant, taking over as mediator. A dialogue then ensues between the mediator, which may sometimes be the entire audience present at the séance, and the spirit, in which the reasons for the crisis leading to the séance and the chances of eliminating them are discussed. The shaman's identification with a spirit role is often momentary, it comes at different stages in the séance and is susceptible to disturbances. In the course of one séance the shaman may identify with several spirits.

It is worth noting that the area in which role-indentification occurs largely coincides with the areas in which the spirit of the ancestral shaman plays a major role as the initiator of the novice shaman. In these areas, the spirit of the ancestral shaman may also remain as the shaman's chief spirit. In this case the spirit of the ancestral shaman enters the shaman at the séance and speaks through him. This points to the possibility that identification with the spirit role, i.e. the possession-type séance, is linked precisely with the development of family-bound and ultimately clan shamanism. In parts of Central and East Siberia the typical explanation for illness is that a disease spirit has entered the patient's body. During a séance the Yukagir shaman identifies with the roles of both his chief spirit and the disease spirit alternately (Jochelson 1926, 201-205). Both forms of possession are basically similar - the spirit is inhaled with noisy gasps, it speaks through the mouth of the shaman, who manifests it with his whole being. The spirit is deactualized by being blown out. Only the characteristic features of the spirits are manifested in different ways. Since shamanic séances are for the most part precisely healing events, it is scarcely a coincidence that basically parallel spirit and demon possessions appear in the same regions. Thus the explanation for illness "the demon has penetrated the patient" would in turn add to the popularity of the possession-type technique of shamanizing. On the other hand, the possession-type of séance is not the only form of séance found in these areas and the shaman's journey-type also appears. Among the Evenks, for example, there were further séances in which the shaman met the spirits in this world, i.e. in the tent, and also travelled to the upper and lower worlds in their company (Anisimov 1968, 207ff). As a result the shaman might well manifest the roles of the spirit-helpers in different ways during the course of one séance: identifying with the spirit role or in some other way manifesting its presence, and describing its behaviour in words only.

The shaman might also manifest spirit roles without identifying with them 
completely, and create an illusion of communication between several spirit figures appearing simultaneously. In the background is the idea of the meeting of shaman and spirit in such a way that the spirit or spirits remain all the time outside the shaman's body. This dual role of the shaman does not require any active contribution from an assistant or from the audience to carry the séance through; the shaman creates the whole performance before them. As regards the manifestation of spirit roles, the ventriloquism produced, for example, by the Chukchi shaman is brilliantly skilful and the séance takes on the form of a great show in which the shaman brings in one spirit after another (Findeisen 1956, 159-167). 'Dual role' is in this case an inadequate expression, for the shaman sometimes tries to create the illusion of the simultaneous presence of several spirits. As well as in Northeast Asia, the shaman's dual role is a typical means of manifesting supranormal counter-roles in the western parts of Siberia, although the technique of manifestation is more reminiscent of the possession-type than the ventriloquism-type: by his sounds and movements the shaman indicates that a spirit is present. The shaman's songs also contain imitations of the sounds of animals, i.e. zoomorphic spirits. Displays of this type are sometimes difficult to distinguish from those of the possession type. According to Munkácsi, for example, the possession tradition might be found among the Khants, whereas Karjalainen, on the basis of his own subsequent experiences, puts this claim open to doubt (Karjalainen 1918, 593). The typical dual role situation of the west is found in the shamanizing séance of the Minusa Tatars (Lankenau 1872, 281-283). It is the specific duty of the assistant to sprinkle water for the spirtis to drink so that they do not come too close to the shaman. Even so the shaman, by imitating the sounds, for example, of a zoomorphic spirit, indicates that it is present, and creates the direct illusion of a conversation between the shaman and the spirit.

Describing the supranormal counter-roles in songs is a common element of the invocation of the spirits. In many cases the course of the entire séance is expressed through song. The shaman meets the spirits in either this or the other world, describing his meeting and his conversations in the songs. It is sometimes difficult to draw a line with the former mode of behaviour, and the presentation of the spirit roles purely by description is also more common in the northern and western parts of Siberia than in the central and eastern regions. Particularly the rich song tradition of the Samoyeds, with its visionary themes, is suitable for carrying out séances of this type (Lehtisalo 1924, 152-155). It is natural that at séances in which the shaman's soul is thought to depart for the supranormal world these experiences are described in the songsections. In this case the outward journey, for example, may be described in song, the arrival there is marked by loss 
of consciousness, and the return journey again in song. The séance basis typical of the northern regions, performed by means of visionary songs, is always the jorney of the shaman's soul. The special nature of this type of séance is revealed when contrasted with the ways of manifesting the shaman's journey employed by e.g. the Evenks and the Nanays. If it was an important and difficult undertaking they might become great shows the setting for which - the objects laid out, the shamanizing site, etc. - was prepared beforehand. The shaman manifested the stages of his journey and the counter-roles he met on the way both through frenzied movement and singing, and also through mimicry. The number of people attending big séances such as this, typical of clan shamanism, was sometimes so great that similar events would have been impossible among the small hunting communities of the north.

\section{Role-taking and control of the degree of altered consciousness}

The ways of manifesting supranormal counter-roles in the shamanic séance thus vary from total involvement by the shaman in living out the role to a mere outlining of the counter-role. We noticed that role-identification, the playing of a dual role or verbal description of a counter-role are, on the one hand, typical behaviour models bound to tradition, but that on the other hand the intensity with which the shaman lives a counter-role varies even in the course of a single séance. The latter point means that the depth of the trance varies according to the course of the séance. The variations in intensity are understandable when we remember that 1) the role relationship of the séance is in fact made up of a triad, for in addition to the shaman and the supranormal role figures he creates there must always be a third party at the séance: the audience, and that 2) the séance always has a goal, something the shaman bears in mind during his actions. As a result, the shaman always has two sorts of other-roles, radically differing in nature, in operation at the séance. For the séance to be duly conducted he must direct his role-taking at the representative or representatives of either group according to need, i.e. during the séance the target groups for the shaman's role-taking change. Then it must be noted that in directing his role-taking at one other-group, the illusory spirit roles, the shaman to a greater or lesser extent keeps an eye on the reactions of the second other-group, the representatives of the community present. Since the supranormal counter-roles act primarily as the objects of reincarnation and identification for the shaman, this other group might be called the identification group. Correspondingly the "clients" taking part in the séance, neighbours or relations who guide the shaman's behaviour by their wishes and reactions, are called the audience group. The role adopted by the shaman with regard to the 
supranormal is therefore dictated by the extent to which he follows the reactions of the audience group or factors connected with the traditional execution of the séance. Alternative forms of role-taking may thus be examined from the standpoint of role-taking or its reflexiveness. ${ }^{10}$ The latter refers to the shaman's self-consciousness - his awareness of how he appears in the eyes of others - and is characteristic precisely of role-taking directed at the audience. Role-taking directed at the audience does not include identification, either; its starting point is selective consideration of the hopes of the audience and the correct execution of the rite. In the light of the above criteria the chief types of 'shaman-supranormal' relations would appear to be as follows:

'Shaman-supranormal' relation

\begin{tabular}{|c|c|c|c|}
\hline & A. Dual role & $\begin{array}{l}\text { B. Role- } \\
\text { identification }\end{array}$ & $\begin{array}{l}\text { C. Verbal con- } \\
\text { struction of role }\end{array}$ \\
\hline $\begin{array}{l}\text { Reflexiveness } \\
\text { of role-taking: }\end{array}$ & Reflexive & $\begin{array}{l}\text { Reflexive and } \\
\text { non-reflexive }\end{array}$ & Non-reflexive \\
\hline $\begin{array}{l}\text { Role-taking } \\
\text { stand point: }\end{array}$ & The audience & $\begin{array}{l}\text { The spirit role } \\
\text { (and the } \\
\text { audience) }\end{array}$ & $\begin{array}{c}\text { The shaman (his } \\
\text { previous vision } \\
\text { experiences) }\end{array}$ \\
\hline Depth of trance: & Light trance & $\begin{array}{l}\text { Depth of trance } \\
\text { varies-comes } \\
\text { in waves }\end{array}$ & $\begin{array}{l}\text { Trance deep, } \\
\text { most often ends } \\
\text { in loss of } \\
\text { consciousness }\end{array}$ \\
\hline
\end{tabular}

The shaman's role-taking with regard to the supranormal, not merely a cognitive process at the séance, but finding an outlet through this process in active operation, the manifestation of roles, thus varies in intensity, influencing the degree of change in the shaman's consciousness. In this respect type $\mathrm{A}$ is in a different position to types $\mathrm{B}$ and $\mathrm{C}$. Keeping an eye on the reactions of the audience requires a stronger link with waking reality (A) than complete identification with the spirit role (B). In the latter case, the responsibility for directing the rite is in fact transferred to the assistant, whose job is also to help the shaman, where necessary, return from too deep a trance. Séances in which the construction of supranormal roles takes place at a verbal level (C), i.e. in the shaman's songs, permit in turn the

${ }^{10}$ See Ralph H. Turner's article "Role-taking, role-standpoint, and reference-group behavior', 1956. 
greatest concentration on supranormal reality. To use Shor's concepts (see p. 108), the direction of the shaman's generalized reality orientation is replaced by complete special temporary orientation. Séances of this type very often end in complete loss of consciousness; all in all, the curve showing the shaman's ecstatic frenzy is simpler - often consisting of a rise, climax and fall - than in séances in which the shaman must be constantly aware of the audience's reactions, or where identification and audience groups change repeatedly as the objects of the shaman's role-taking. In this case, the curve showing the shaman's ecstasy is wave-like, with several climaxes. Although the part played by the audience as a suggestive factor can under no circumstances be denied - on the contrary, it does exert some sort of basic pressure on the shaman's quest for ecstasy and also provides active support for the shaman during the séance - it is nevertheless clear from the accounts of séances that when the roletaking is directed at the audience the degree of the shaman's altered consciousness falls just as it rises when role-taking is directed at the supranormal world.

The relationship between the shaman and the audience attending the séance, which influences ecstatic activity, is determined according to the position of the shaman and shamanism in the community. It is interesting to note that among the Chukchi Type A (dual role) manifestation of the supranormal based on ventriloquist skill was held in greater esteem than type C (verbal construction of role), typical of small group shamanism in northern Siberia and connected with the shaman's journey. The former type of séance, in which the shaman was able to observe the audience's reactions throughout the performance, is in fact more suited to the independent professional shaman seeking the favour of the audience than is the latter form. The Chukchi's manner of bringing in the spirit roles, which demanded great skill, and the great show-like shaman events of the southern regions have been mistakenly regarded as indications of the degeneration of shamanism merely because there was seldom a loss-of-consciousness stage. In the case of rite performances involving a wealth of requisites and many episodes, it is rather a question of more developed forms of tradition, reflecting the importance and scope of the shaman in the community rather than a degeneration in the shaman's ecstatic ability.

\section{References}

Allen, V. L.-Sarbin, T. 1964. Role enactment, audience feedback, and attitude change. Sociometry 27.

Anisimov, A. F. 1963. The shaman's tent of the Evenks and the origin of the shamanistic rite. Studies in Siberian shamanism, ed. by H. N. Michael. (Arctic Institute of North America. Translations from Russian sources 4.) Toronto. 
- 1958. Religija évenkov. Moskva-Leningrad.

Bányai, E. I. 1980. A new way to induce a hypnotic-like altered state of consciousness: active-alert induction. Problems of the regulation of activity (4th meeting of psychologists from the Danubian countries). Budapest.

Bányai, E. I.-Hilgard, E. R. 1976. A comparison of active-alert hypnotic induction with traditional relaxation induction. Journal of abnormal psychology 85. Stanford, Cal.

Bányai, E. I., Mészáros, I.-Greguss, A. C. 1980. Alteration of activity level: the essence of hypnosis or a byproduct of the type of induction? 28th International congress of physiological Sciences. Budapest.

Bogoras, W. 1904-1909. The Chukchee. The Jesup North Pacific Expedition, ed. by F. Boas. (Memoir of the American Museum of Natural History 7.) Leiden, New York.

Cooley, C. H. 1972. Looking-glass self. Symbolic interaction, a reader in social psychology, ed. by J. G. Manis and B. N. Melzer, Boston.

Diószegi, V. 1960. Tracing shamans in Siberia. Oosterhout.

Findeisen, H. 1956. W. G. Bogoras' Schilderung zweier schamanischer Séancen der. Küsten-Tschuktschen (Nordost-Sibirien). Abhandlungen und Aufsätze aus dem Institut für Menschen- und Menschheitskunde 38. Augsburg.

Fischer, R. 1969. The perception-hallucination continuum (a re-examination). Diseases of the nervous system 30 .

- 1970. Prediction and measurement of perceptual-behavioral change in druginduced hallucinations. Origin and mechanism of hallucinations, ed. by W. Keup. New York.

Gill, M. M.-Brenman, M. 1959. Hypnosis and related states: psychoanalytic studies in regression. New York.

Harner, M. J. 1973. Hallucinogens and shamanism. London, Oxford and New York.

Honko, L. 1969. Role-taking of the shaman. Temenos 4.

- 1972. Rooliteorian soveltamisesta uskontotieteessä. L. Honko, Uskontotieteen näkökulmia. Helsinki.

Hudjakov, I. A. 1969. Kratkoe opisanie Verhojanskogo okruga. Pod red. V. G. Bazanova. Leningrad.

Jochelson, W. 1926. The Yukaghir and the Yukaghirized Tungus. The Jesup North Pacific Expedition, ed. by F. Boas. (Memoir of the American Museum of Natural History 9.) New York.

Karjalainen, K. F. 1918. Jugralaisten uskonto. Porvoo.

Lankenau, H. v. 1872. Die Schamanen und das Schamanenwesen. Globus 22.

Lehtisalo, T. 1924. Entwurf einer Mythologie der Jurak-samojeden. Mémoires de la Société Finno-ougrienne 53. Helsinki.

- 1947. Juraksamojedische Volksdichtung. Mémoires de la Société Finno-ougrienne 90 . Helsinki.

Lopatin, I. A. 1946-1949. A shamanistic performance for a sick boy. Anthropos $41-44$.

- 1960. The cult of the dead among the natives of the Amur Basin. (Central Asiatic Studies 6.) 's-Gravenhage.

Ludwig, A. M. 1968. Altered states of consciousness. Trance and possession states, ed. R. Prince. Montreal.

Mead, G. H. 1934. Mind, self and society. Chicago. 
Neher, A. 1962. A physiological explanation of unusual behavior in ceremonies involving drums. Human biology 34.

Peters, L. G.-Price-Williams, D. 1980. Towards an experiential analysis of shamanism. American ethnologist 7.

Prince, R. 1968. Can the EEG be used in the study of possession states? Trance and possession states, ed. R. Prince. Montreal.

Sarbin, T. 1950. Contributions to role-taking theory: 1. Hypnotic behavior. Psychological review 57.

- 1954. Role theory. Handbook of social psychology, ed. G. Lindzey and E. Aronson 1. Cambridge, Mass.

Shirokogoroff, S. M. 1935. Psychomental complex of the Tungus. London.

Shor, R. E. 1959. Hypnosis and the concept of the generalized reality-orientation. American journal of psychotherapy 13.

Siikala, A.-L. 1978. The rite technique of the Siberian shaman. (FF Communications 220.) Helsinki.

- 1979. Kärpässienen rituaalinen käyttö pohjoisessa Euraasiassa. Alkoholipolitiikka 44.

- 1980. Two types of shamanizing and categories of shamanistic songs. A Chukchi case. Genre, structure and reproduction in oral literature, eds. L. Honko and V. Voigt. Budapest.

Strunk, O. 1962. Religion. A psychological interpretation. New York, Nashville.

Sundén, H. 1959. Religionen och rollerna. Ett psykologiskt studium av fromheten. Stockholm.

Turner, R. H. 1956. Role-taking, role standpoint, and reference-group behavior. American journal of sociology 61.

van der Walde, P. H. 1968. Trance states and ego psychology. Trance and possession states, ed. R. Prince. Montreal.

Walker, S. S. 1972. Ceremonial spirit possession in Africa and Afro-America. Leiden.

Walter, V. J.-Walter, W. G. 1949. The central effects of rhythmic sensory stimulation. Electroencephalography and clinical neurophysiology 1.

White, R. M. 1941. A preface to the theory of hypnotism. Journal of abnormal and social psychology 36. 